search work started well in time can produce a better end product than one started at the last minute. Students are able to understand the turnaround time of obtaining materials that are not readily available. In addition, students will be able to devote the end of the semester to reviewing their materials for final examinations, rather than combining the pressure of turning in a paper with the tedious process of getting ready for examinations.

Term paper counseling sessions are very useful to the students we deal with. However, unless these sessions are started early enough in and continued throughout the semester, the laudable intentions of librarians can be thwarted as a result of congestion at the reference desk during the last days of the semester. Our semester-long term paper counseling sessions have brought peace and quiet to the reference desk at the end of the semester. However, as one could have guessed, there are still many students who will never subscribe to our concept of early start on their papers. They still come in at the last minute, filled with anxiety, armed with impatience, and ready to negotiate for extended library hours to be able to finish their papers on schedule.

\title{
Humor and creativity: MLS envy
}

\author{
By J. C. Bennett
}

\author{
Assistant Professor of Library Science \\ Eastern New Mexico University
}

In any field, subordinates who feel that they can capably perform the work of their superiors may create difficulties. In libraries, paraprofessionals cause severe logical dilemmas for professional librarians when they espouse this feeling, herein termed "MLS envy." MLS envy is a stage of the paraprofessional's development into a loyal, hardworking flunky. Avoiding it requires that paraprofessionals be made to feel more positive about their inability to rise above a trivial rank. Like all psychological phases, MLS envy must be resolved before paraprofessionals can be said to be fully mature. They must be willing to accept the second-class status their position entails.

MLS envy requires careful handling. It usually sets in between one and eight weeks after the new paraprofessional begins work. The complex proceeds gradually. At first, subjects foolishly believe that they have intentionally been given their department's most monotonous tasks and that they have little hope of quickly moving on to more interesting assignments. Subjects may irrationally assume that older, more experienced paraprofessionals must perform tasks only slightly less tedious than their own. MLS envy is well on its way when subjects feel that they are being treated unjustly by being paid half or less of the starting professional's salary, even though the professionals in question may be younger than the nonprofessionals, hold fewer degrees, and have less employment experience. The complex is full blown when subjects become convinced that they could competently perform professional work without the benefit of an MLS degree.

The symptoms are generally easy to detect. In the early stages subjects are restless and uneasy, doubt the wisdom of superiors, and may feel disenchanted with their work. Such feelings become stronger as time passes, until the complex is truly visited on them. At that point, deep problems arise. Subjects may become bitter, insolent, lazy, and unmanageable; they may harbor thoughts of quitting without notice; they may be habitually absent or unbearably late with only poor excuses. Through all this they deserve sympathy and mercy, and a strong hand to guide and lead them along a path of reason and sense.

To move forward, resolution of the internal conflict is necessary. If subjects are to live happy, contented lives as paraprofessionals, they must believe in their supervisors and trust them to do what is best, no matter how painful it may be. If, after a grace period of several weeks after the onset of erroneous thoughts, subjects are unwilling or unable to submit completely, they are unlikely to progress very far, and will stay fixated at an irrational stage for the rest of their paraprofessional careers. Their superiors will then be wise to seriously consider terminating them with the merciful hope that they will prostrate themselves more readily in another field. If the superiors decide not to do so, they must be willing to work closely with sub- 
jects to resolve irrational feelings.

A male paraprofessional trying to move beyond MLS envy may be especially uneasy around a female professional librarian. After all, he does not have one, while she does. Despite their intention to accept inferiority, subjects may regard professionals as a threat to their intelligence and critical thought. If their supervisors are sensitive, they may hasten the resolution of the situation with wellchosen words and instructions. They must help the subjects to understand, accept, and be happy in their place in the library world. They must patiently explain as often as necessary that the MLS degree is absolutely essential for professional work, and that the subjects, competent as they may be at their own tasks, are unfit to assume such positions. If at any time subjects question them, citing studies which show that some paraprofessionals can adequately perform professional duties, 't their protests

'Deborah Kirk, "Mission Possible: Elementary Library/Media Centers without Professionals," Colorado Libraries, December 1986; John S. Goodell, A Case Study of Catalogers in Three University Libraries (Ann Arbor, Mich, : University Microfilms, 1971); Charles A. Bunge, Professional Education and Reference Efficiency (Springfield, Ill.: Illinois State Library, 1967); John A. McCrossan, Library Science Education and Its Relation-

\section{Standards for university libraries document available}

The 1989 revision of the "Standards for University Libraries: Evaluation of Performance," which appeared in the September 1989 issue of C¿RL News, pp. 679-91, is now available from the ACRL Office. This standard replaces the previous version dating from 1979.

The standards were prepared by the University Libraries Section's Standards Review Committee, chaired by Kent Hendrickson. They are intended to help members of the library and university administration responsible for determining priorities and evaluating performance to optimize the role of the library in the mission of the university. Basic to this document is the proposition that each university library system is unique and therefore should determine its own criteria for performance and evaluation.

Single copies of the document are available free of charge (additional copies are $\$ 1.00$ each) from ACRL/ALA, $50 \mathrm{E}$. Huron St., Chicago, IL 60611. Call (800) 545-2433; in Illinois, (800) 545-2444; in Canada, (800) 545-2455. Permission is granted to make copies of the standards for noncommercial purposes. must be met with sympathetic but firm disapproval. They must be told to face up to their problems; supervisors must not debate them, for one must not "answer a fool according to his folly lest one be like him." "

Properly managed, the resolution of MLS envy should take no more than six to eight weeks, although a longer period should be allowed for more educated subjects. Once satisfactorily resolved, behaviors characteristic of MLS envy will be abandoned. Subjects will then live confidently and quietly in their subservient roles. Guilt will disappear quickly when supervisors are understanding, and subjects will soon display the loyalty of a prodigal son, providing an exemplary, ne'er-say-negative atmosphere among the support staff. In exceptional cases they will be instrumental in helping others to pass through MLS envy with a minimum of discomfort.

There is another manner whereby MLS envy may be resolved, but it is difficult and usually undesirable. It involves a transsocial operation in an American Library Association-approved "clinic." When one carefully compares the method of resolution where subjects emerge as well-adjusted paraprofessionals with this clinical alternative, one can scarcely choose the latter. Subjects must themselves earn the MLS, and bachelors' degrees if they do not already hold them. While the resolution to remain a paraprofessional takes only a few weeks, the MLS requires one to two years of intense therapy. In most cases subjects must travel far from home to complete the degree; there are only about sixty approved "clinics" in which treatment may take place. All this costs a great deal, and little financial assistance other than loans is available.

It must be conceded that the prognosis for those MLS envy sufferers who take the MLS route is good. Once subjects have undergone this operation, they are unlikely to believe that paraprofessionals should compete for professional positions. However the same effect can be more easily and more quickly achieved by either 1) requiring paraprofessionals to resolve their MLS envy or 2) dismissing them to put them out of their misery. One should not call this "censorship" or "discrimination" but "sound personnel policy." To allow persons without MLS degrees to become professional librarians would constitute censorship of library school professors who, without a large number of students, would be denied an ivory tower from which to praise the library profession. Also librarians have an image to maintain; to discount the MLS

ship to Competence in Adult Book Selection in Public Libraries (Springfield, Ill.: Illinois State Library, 1967).

${ }^{2}$ Proverbs 26:4. 
would be to invite public disrespect.

MLS envy and the dangers surrounding it cannot be given too much attention. Successful resolution of this complex is the key to good relations with paraprofessionals, harmonious operations every- where in the library, and the eradication of ignorance. The last of these is, of course, the true mission of librarians. By dispelling MLS envy, librarians are educating and strengthening American society.

\title{
Staff training for a multi-database system
}

\author{
By Ramona J. Steffey \\ Automation Project Librarian \\ Vanderbilt University
}

In January 25, 1989, a new service was implemented for library users at Vanderbilt University. On that day a subset of the National Library of Medicine's MEDLINE database was first made available on public catalog terminals in the Medical Center Library and certain other branch libraries. This new service was the result of over two years of planning and development through an automation effort known as Vanderbilt's Enhanced Information Access Project, partially funded by a $\$ 750,000$ grant from the Pew Charitable Trusts.

A primary goal of the Enhanced Information Access (EIA) Project was to provide access to article level databases through the developing campus-wide broadband network. Inquiries were made to several major companies in the field of automation and an agreement was made with NOTIS Systems, Inc., to participate in this endeavor. Vanderbilt had already been successful in implementing NOTIS's Library Management System, having made the online catalog available in September 1985 and other modules (e.g. circulation, serials control, acquisitions) soon thereafter. Vanderbilt's objective in the EIA Project fit into NOTIS's long-range plan of adding multiple database access to its integrated online system.

Following a meeting with key NOTIS and Vanderbilt staff in January 1987, work began on what came to be known as Vandy 1. The results of Vandy $l$ are access to MEDLINE using NOTIS search commands and the capability of database selection and effortless switching from one database to another. This portion of the project was considered complete when the system became available to the public on January 25. The second phase of the NOTIS project, known as Vandy 2, will make three of the H.W.Wilson databases available in the same environment and is scheduled to be complete this spring. We have subscribed to the tapes for General
Science Index, Humanities Index, and Social Sciences Index.

NOTIS is expanding on the development work done with Vanderbilt and is marketing its "Multiple Database Access" product to other NOTIS customers. The finished product, which will be available this summer, provides the conversion programs for MEDLINE and H. W. Wilson and adds a greater flexibility to the system's inherent design, making it possible for a non-programmer to add new databases and modify screens. We at Vanderbilt have already started planning for loading tapes from the Center for Research Libraries as another option on our system. We will continue to work with NOTIS on further enhancements to the multiple database product.

Planning for staff training began long before the database became available to the public. As with the public catalog, online help screens were predicted to be the most important tools for training, both for staff and library patrons. Vanderbilt staff used as a base the LUIS screens provided by NOTIS. Modifications were made to highlight the unique features and fields of MEDLINE. Since we anticipated that many users would eventually be using the database from remote sites, we wanted the help screens to convey as much information as possible.

In addition to help screens, we prepared a brief brochure, or Quick Reference Guide, which could be given to patrons and made available at terminals. This guide covered the basic search commands, Boolean and positional operators, and tips for searching. Field qualifiers for keyword searching, the stopword list, language codes, and journal subset codes were listed. Also listed were the MeSH Check Tags and abbreviations for MeSH subheadings along with tips for searching these.

Training sessions began immediately after the 